\title{
Unscheduled bleeding on HRT - do we always need to investigate for endometrial pathology?
}

\author{
Ying Yiing Lou ${ }^{1 *}$, Jeyanthan Kannappar², Sahathevan Sathiyathasan ${ }^{3}$
}

\begin{abstract}
${ }^{1}$ Department of Obstetrics and Gynecology, Watford General Hospital, Vicarage Road, Watford, WD18 0HB, UK ${ }^{2}$ Department of Obstetrics and Gynecology, Barnet General Hospital, Wellhouse Lane, Barnet, EN5 3DJ, UK ${ }^{3}$ Department of Obstetrics and Gynecology, Princess Royal University Hospital, Farnborough Common, Orpington, BR6 8ND, UK
\end{abstract}

Received: 25 July 2017

Accepted: 22 August 2017

\section{*Correspondence:}

Dr. Ying Yiing Lou,

E-mail: yingyiing.lou@nhs.net

Copyright: (C) the author(s), publisher and licensee Medip Academy. This is an open-access article distributed under the terms of the Creative Commons Attribution Non-Commercial License, which permits unrestricted non-commercial use, distribution, and reproduction in any medium, provided the original work is properly cited.

\begin{abstract}
Hormone replacement therapy (HRT) is the most effective method for relieving the effects of hypoestrogenism following menopause. Despite the benefit of the HRT, unscheduled/breakthrough bleeding decreases patients' compliance with long-term use. The underlying mechanisms for this unpredictable breakthrough bleeding are less well understood. In the event of unscheduled bleeding, investigation may be necessary according to local protocol. Whilst the incidence of underlying benign pathology may be quite high, the likelihood of malignancy is low and unless there is particular clinical concern, these women do not need fast track referral which should be reserved for women with true postmenopausal bleeding.
\end{abstract}

Keywords: Breakthrough bleeding, Hormone replacement therapy, Menopause, Unscheduled bleeding

\section{INTRODUCTION}

Peri and postmenopausal hormone replacement therapy (HRT) is the most effective treatment for symptoms of oestrogen deficiency. Unscheduled or breakthrough bleeding on HRT is a common problem in postmenopausal women. It is one of the biggest causes of dissatisfaction with HRT and is often the single most important factor deterring women from continuing to use of HRT.

With advancing age, the potential for underlying pathology increases, thus the two main strategies in managing irregular bleeding on HRT are first to exclude endometrial pathology and second to correct the irregular bleeding.

The mechanisms that underlie this unscheduled bleeding are poorly understood. Thus, the occurrence of unscheduled bleeding with HRT may provide a dilemma with diagnosis as well as a challenge to acceptability.

\section{HRT regimens}

Both sequential (combined cyclical) and continuous combined HRT regimens were developed to result in the patient having predictable bleeding or to have no bleeding at all. ${ }^{1}$ (Table 1$)$. 
Table 1: Summary of HRT treatment regimens. ${ }^{2}$

\begin{tabular}{|c|c|c|}
\hline Non-hysterectomised & & Hysterectomised \\
\hline Perimenopausal & Postmenopausal & \multirow{2}{*}{ Oestrogen only } \\
\hline Sequential regime & Continuous combined regime & \\
\hline $\begin{array}{l}\text { Continuous oestrogen/ cyclical progestogen for } \\
10-14 \text { days in } 28 \text {-day cycle, giving cyclical } \\
\text { progestogen withdrawal bleed. } \\
\text { Consider changing to continuous combined } \\
\text { HRT when postmenopausal or } 54 \text { years }\end{array}$ & $\begin{array}{l}\text { Cycle free HRT, continuous } \\
\text { oestrogen and progestogen / } \\
\text { progesterone }\end{array}$ & $\begin{array}{l}\text { Prescribe continuous combined } \\
\text { oestrogen and progestogen } \\
\text { - If history of severe endometriosis } \\
\text { - Occasionally after subtotal } \\
\text { hysterectomy, the decision is made } \\
\text { by the surgeon }\end{array}$ \\
\hline
\end{tabular}

\section{Sequential HRT}

It is a common practice to administer sequential regimens of oestrogen and progestogen while women are still perimenopausal and therefore experiencing some erratic secretion of endogenous follicular oestradiol. ${ }^{3}$ The progestogen phase of HRT should coincide with the luteal phase of the cycle, which is the last 12-14 days of the cycle. Although natural cycle lengths may vary considerably, the luteal phase is consistent. Thus, for a 28-day cycle progestogen should start around Day 15-17 and for a 35-day cycle they should start around Day 21.

This type of sequential regimen appears to minimise the likelihood of breakthrough bleeding occurring at this stage of life although it is not sufficient to inhibit endogenous ovarian activity unlike the combined oral contraceptive pill. ${ }^{4}$ In most sequential regimens, oestrogen is taken on a continuous daily basis and a progestogen is given for at least 10 days each month with a coordinated withdrawal bleed following 1-3 days after the end of the progestogen course. Unscheduled bleeding sometimes occurs following episodes of endogenous follicular oestradiol secretion.

\section{Continuous combined HRT}

Once a woman has become clearly postmenopausal, there is an increasing tendency towards use of continuous combined preparations with the underlying principle is that progestogen is continuously added to oestrogen to oppose the proliferative effects of oestrogen on the endometrium and thus prevent bleeding.

This usually brings about a state of considerable endometrial thinning close to atrophy, leading sooner or later to amenorrhoea. The dose of progestogen is kept relatively low, but high enough to permit greatly suppressed secretory or 'atrophic' transformation of the endometrium and to prevent endometrial hyperplasia and malignancy. $^{3}$

\section{Causes of unscheduled bleeding on HRT}

In the sequential regimen, irregular bleeding is expected to occur in $8 \%$ to $40 \%$ of users. ${ }^{5-7}$ More than half of users of this regimen may bleed before day 11 of the progestogen sequence and less than $10 \%$ of women may experience recurrent episodes of breakthrough bleeding. ${ }^{8}$ On the other hand, the percentage of women with abnormal bleeding on the combined continuous regimen, either oral or transdermal, ranges from, $0 \%$ to $77 \%$ in the first few years of treatment. ${ }^{7,9,10}$

With the continuous regimen, the percentage of women with bleeding decreases after 6 to 12 months of use and after 9 months, it is expected that only $3 \%$ to $10 \%$ will still present this complication. ${ }^{11}$ In the transdermal route, the percentage of women who still present bleeding or spotting after 12 months of use ranges from $10 \%$ to $20 \% .^{12}$

\section{Certain clinical factors may correlate with unscheduled} bleeding and spotting and include

- $\quad$ Poor compliance-women forgetting to take tablets.

- Intrauterine pathology, especially endometrial polyps and submucosal fibroids occurring in up to $40 \%$ of women. ${ }^{13}$

- Proximity of women to the menopause. Perimenopausal women appear more likely to experience breakthrough bleeding on continuous combined regimens than women who are fully menopausal. This is presumably because perimenopausal women still have erratic endogenous ovarian follicular activity. ${ }^{14}$

- Higher endogenous oestrogen production in women with obesity. After the menopause, endogenous oestrone (and thus some oestradiol) is produced from a number of sources by peripheral conversion of androgens. This is well documented in adipose tissue and women with more fat stores may experience a higher endogenous production of oestrogen, with consequent action on the endometrium. ${ }^{15}$

The risk of endometrial hyperplasia associated with sequential HRT over approximately 3 years is around $2.7-5 \% .{ }^{16}$ With tricyclic HRT it may be as high as $11 \% .{ }^{17}$ Conversely, the risk of endometrial hyperplasia with continuous combined HRT is less than $1 \% .{ }^{18}$ Indeed, continuous progestogen is an effective method of converting hyperplasia back to normal. ${ }^{16}$ Recent 
epidemiological studies have indicated that more than 5 years of sequential HRT in postmenopausal women is associated with a three-fold increase in endometrial cancer risk whereas continuous combined progestogen addition was associated with a four- to five-fold reduction in cancer risk. ${ }^{19}$ On the basis of these results women should be advised to switch to continuous combined combinations once they are 5 or more years past menopause.

\section{Management of unwanted bleeding}

Although bleeding problems are common with HRT there are very few studies that have specifically looked at strategies to overcome them.

\section{Sequential HRT}

$85 \%$ women on sequential HRT get a regular withdrawal bleed and up to $15 \%$ have no bleeding. ${ }^{20}$ Synchronisation with any endogenous activity is necessary. The progestogen phase of HRT should coincide with the luteal phase of the cycle, which is the last 12-14 days of the cycle. Although natural cycle lengths may vary considerably, the luteal phase is consistent. If cycle control remains difficult, a higher dose of progestogen may be necessary. The monophasic, low-dose oral contraceptive can also be used, the higher potency being strong enough to suppress endogenous activity. The levonorgestrel intrauterine system (IUS) is an alternative option, although unlicensed.

The withdrawal bleed should occur at the end of the progestogen phase. If the withdrawal bleed is heavy or prolonged or occurs too early, then increasing the dose or changing the type of progestogen may be helpful. Spotting before the withdrawal bleed may represent inadequate endometrial stromal formation and a higher oestrogen dosage could be used. If bleeding problems are persistent then referral for further investigation should be considered.

\section{Continuous combined HRT}

Amenorrhoea is achieved by 6 months in the majority of women. Once amenorrhoea is achieved it is usually maintained. Those furthest from the menopause appear to have the highest incidence of amenorrhoea. ${ }^{21}$

In the absence of clinical signs or other risk factors, bleeding between 3 and 6 months is usually considered to be acceptable but persistent bleeding after 6 months or bleeding commencing after a spell of amenorrhoea should always be investigated.

In the absence of endometrial pathology, increasing the dose or changing the progestogen may help. Bleeding problems are less with lower dose preparations but there are some women who seem to bleed persistently on continuous combined HRT. A small oestrogen supplement may help in some women but if all fails then the women may be best advised to revert to sequential HRT and a regular bleed. Whilst the levonorgestrel IUS is another option, persistent spotting with this method cannot be ruled out. Endometrial resection has been suggested but the justification for such a surgical procedure needs to be quite strong. ${ }^{22}$

\section{Investigation of abnormal bleeding}

The principal aim of the investigation of postmenopausal bleeding is to identify or exclude endometrial pathology, most notably endometrial carcinoma. This should involve a pelvic examination and at least one of: transvaginal ultrasound scan (TVUS), hysteroscopy or endometrial biopsy.

\section{Transvaginal ultrasounography}

TVUS can reliably assess thickness and morphology of the endometrium and can thus identify a group of women with postmenopausal bleeding who have a thin endometrium $<5 \mathrm{~mm}$ and are therefore unlikely to have significant endometrial disease. This group may not require any further investigation unless there is a recurrence of bleeding. ${ }^{23}$

\section{Endometrial thickness cut-off}

A meta-analysis reviewed evaluations of TVUS. ${ }^{24}$ After lower quality studies had been excluded (those associated with a higher risk of bias that might affect estimates of test accuracy), only four high quality studies remained. These four studies all assessed the $5 \mathrm{~mm}$ threshold and, when pooled, showed that a negative TVUS result of 5 $\mathrm{mm}$ or less reduced the risk of disease by $84 \%$. Whether this is sufficient to rule out disease depends on the pretest risk of disease in the relevant patient group. Furthermore, the authors caution against relying on the pooled findings of only four studies, for which there is a wide $95 \%$ confidence interval for the reduction in risk (54\% to $94 \%$ ) arising from a negative result.

The mean endometrial thickness in women on sequential hormone replacement therapy with postmenopausal bleeding is greater than in those women with postmenopausal bleeding who are not on sequential HRT. Thus, an abnormal endometrial thickness in women with postmenopausal bleeding who are not using sequential HRT represents a greater probability of endometrial disease than in women taking hormone replacement therapy. ${ }^{25}$ In women using sequential HRT, the thickness of the endometrial wall can vary with each phase of the cycle. In order to standardise readings, TVUS measurements should probably take place during the first half of the cycle.

For women on sequential HRT an endometrial thickness above $8 \mathrm{~mm}$ should be investigated as endometrial thickness of $8 \mathrm{~mm}$ or less is unlikely to be associated 
with malignant pathologies in premenopausal uterine bleeding. ${ }^{26}$

\section{Endometrial biopsy}

A definitive diagnosis in postmenopausal bleeding is made by histology. Outpatient endometrial sampling has a procedure failure rate as well as a tissue-yield failure rate, each of approximately $10 \% .{ }^{27}$ Hysteroscopy allows direct visualisation of the endometrial cavity. A biopsy of the endometrium is usually taken following hysteroscopy by curettage. Despite general consensus that it is the current gold standard, the evidence base for hysteroscopy is poor.

There is no evidence to recommend when reinvestigation should take place following recurrent or persisting postmenopausal bleeding. It is suggested that re-investigation of recurrent postmenopausal bleeding should be considered after six months. ${ }^{28}$

\section{Continuation of HRT prior to investigation}

Use of HRT generally leads to thickening of the endometrial lining, whereas continuous combined HRT causes endometrial atrophy. There is uncertainty as to whether HRT should be stopped or not prior to investigation for PMB.

There is unlikely to be any problem in histological interpretation if the patient remains on HRT provided the pathologist is given details of the hormonal treatment. In addition, the pathologist may be able to identify changes in the endometrium that are hormonally induced and could explain the abnormal or unscheduled bleeding. Alternatively, by stopping HRT and inducing an oestrogen withdrawal bleed, tissue may theoretically be lost that should be assessed. In addition, stopping HRT before investigation may transmit the wrong signals to patients regarding the risks of HRT. ${ }^{29}$ Whether or not to continue HRT use prior to investigation may depend on the patient's wishes and how long she has to wait for investigations but there is no specific reason for discontinuing it.

\section{CONCLUSION}

Unscheduled bleeding problems are common with both sequential and continuous combined preparations and may result in disillusionment and early discontinuation of treatment. Choosing the correct type of preparation from the outset and understanding the mechanism of abnormal bleeding during hormonal therapy are one of the keys to the successful prescribing of HRT. If unscheduled bleeding persists after the first 6 months in continuous combined HRT, this warrants endometrial assessment.

Funding: No funding sources Conflict of interest: None declared

Ethical approval: Not required

\section{REFERENCES}

1. Staland B. Continuous treatment with natural estrogens and progestogens, A method to avoid endometrial stimulation. Maturitas. 1981;3:145-6.

2. Rees M, Stevenson J, Hope S. (Eds.) Management of the menopause: the handbook. 5th edition. London/Marlow: Royal Society of Medicine Press Ltd \& British Menopause Society Publications Ltd; 2009.

3. Hickey $\mathbf{M}$, Elliot $\mathbf{J}$ and Davison SL. Hormone replacement therapy. BMJ. 2012;344:e763.

4. Gebbie AE, Glasier A. and Sweeting V. Incidence of ovulation in perimenopausal women before and during hormone replacement therapy. Contracept. 1995;52:221-2.

5. Archer DF, Pickar JH, Bottiglioni F. The Menopause Study Group. Bleeding patterns in postmenopausal women taking continuous combined or sequential regimens of conjugated estrogens with medroxyprogesterone acetate. Obstet Gynecol. 1994;83:686-92.

6. Al-Azzawi, Wahab M, Thompson J, Whitehead M, Thompson W. Acceptability and patterns of uterine bleeding in sequential trimegestone-based hormone replacement therapy: a dose-ranging study. Hum Reprod. 1999;14:636-41.

7. Di Carlo C, Sammartino A, Sardo ADS. Bleeding patterns during con $\neg$ tinuous estradiol with different sequential progestogens therapy. Menopause. 2005;12:520-5.

8. Al-Azzawi F, Habiba M. Regular bleeding on hormone replacement ther $\neg$ apy: a myth? Br J Obstet Gynaecol. 1994;101:661-2.

9. Rossouw JE, Anderson GL, Prentice RL. Risks and benefits of estrogen plus progestin in healthy postmenopausal women: principal results from the Women's Health Initiative randomized controlled trial. JAMA. 2002;288:321-3.

10. Archer DF. Endometrial bleeding in postmenopausal women: with and without hormone therapy. Menopause. 2011;18:416-20.

11. Ettinger B, Li DK, Klein R. Unexpected vaginal bleeding and associated gynecologic care in postmenopausal women using hormone replacement therapy: comparison of cycles versus continuous combined schedules. Fertil Steril. 1998;69:865.

12. Oosterbaan HP, van Buuren AHJAM, Schram JHN. The effects of continuous combined transdermal oestrogen-progestogen treatment on bleeding patterns and the endometrium in postmenopausal women. Maturitas. 1995;21:211-9.

13. Nagele F, O'Connor H, Basket TF. Hysteroscopy in women with abnormal uterine bleeding on hormone replacement therapy: a comparison with postmenopausal bleeding. Fertil Steril. 1996; 65:1145-50.

14. Sturdee DW. Irregular bleeding on HRT. Menopause Digest. 1988;5:6-7. 
15. Kaaks R, Lukanova A, Kurzer MS. Obesity, endogenous hormones, and endometrial cancer risk: a synthetic review. Cancer Epidemiol Biomarkers Prev. 2002;11(12):1531-43.

16. Sturdee DW, Ulrich LG, Barlow DH. The endometrial response to sequential and continuous combined oestrogen-progestogen replacement therapy. Br J Obstet Gynecol. 2001;107:1392-400.

17. Cerin A, Heldaas K, Moeller B. Adverse endometrial effects of long cycle estrogen and progestogen replacement therapy. N Engl J Med. 1996;334:668-9.

18. Archer DF, Pickar JH, Bottiglioni F. Bleeding patterns in postmenopausal women taking continuous combined or sequential regimens of conjugated estrogens with medroxy-progesterone acetate. Obstet Gynecol. 1994;83:686-92.

19. Beresford SA, Weiss NS, Voigt LF. Risk of endometrial cancer in relation to use of oestrogen combined with cyclic progestogen therapy in postmenopausal women. Lancet. 1997;349:458-61.

20. Whitehead MI, Hillard TC, Crook D. The role and use of progestogens. Obstet Gynecol. 1990;75:55976.

21. Archer DF, Dorin MH, Heine W. Uterine bleeding in postmenopausal women on continuous therapy with estradiol and norethindrone acetate. Obstet Gynecol. 1999;94:323-9.

22. Romer T. Treatment of recurrent bleeding disorders during hormone replacement therapy (HRT) by transcervical endometrial ablation. Gynecol Obstet Invest. 1999;47:255-7.

23. Dijkhuizen FP, Brolmann HA, Potters AE, Bongers MY, Heintz AP. The accuracy of transvaginal ultrasonography in the diagnosis of endometrial abnormalities. Obstet Gynecol. 1996;87:345-9.
24. Chien PFW, Voit D, Clark TJ, Khan KS, Gupta JK. Ultrasonographic endometrial thickness for diagnosing endometrial pathology in women with postmenopausal bleeding: A meta-analysis. Acta Obstet Gynecol Scand. In press; 2002.

25. Granberg S, Ylostalo P, Wikland M, Karlsson B. Endometrial sonographic and histologic features in women with and without hormonal replacement therapy suffering from postmenopausal bleeding. Maturitas. 1997;27:35-40.

26. Melson L, Hillard TC. The management of abnormal bleeding on HRT - a proposed protocol and early audit of results. J Br Menopause Soc. 2002;4(Suppl. 2).

27. Etherington IJ, Harrison KR, Read MD. A comparison of outpatient endometrial sampling with hysteroscopy, curettage and cystoscopy in the evaluation of postmenopausal bleeding. J Obstet Gynaecol 1995;15:259-62.

28. Investigation of post-menopausal bleeding a national clinical guideline. Scottish Intercollegiate Guidelines Network; 2002.

29. Smith-Bindman R, Kerlikowske K, Feldstein VA, Subak L, Scheidler J, Segal M, et al. Endovaginal ultrasound to exclude endometrial cancer and other endometrial abnormalities. JAMA. 1998;280:1510-7.

Cite this article as: Lou YY, Kannappar J, Sathiyathasan S. Unscheduled bleeding on HRT - do we always need to investigate for endometrial pathology? Int J Reprod Contracept Obstet Gynecol 2017;6:4174-8. 